\title{
Symmetry Coordinates and Force Field Analysis of a Heptamolybdate, $\mathrm{Mo}_{7} \mathrm{O}_{24}$, Model
}

\author{
Lennart E. Lyhamn \\ Department of Inorganic Chemistry, Umeå (Sweden)
}

S. J. Cyvin

Division of Physical Chemistry, University of Trondheim, N-7034 Trondheim-NTH (Norway)

Z. Naturforsch. 34a, 867-875 (1979); received March 15, 1979

\begin{abstract}
A complete vibrational analysis is performed for a heptamolybdate, $\mathrm{Mo}_{7} \mathrm{O}_{24}$, model of $\mathrm{C}_{2 \mathrm{v}}$ symmetry. The symmetry coordinates are classified into those of (a) framework vibrations, (b) ligand vibrations, (c) framework-ligand couplings, and (d) interligand vibrations. A simple valence force field is estimated, and a relative scale for the force constants of the angles is presented. Vibrational frequencies are calculated and the influence of inclusion of redundancies is investigated. The final result is compared with experimental data from infrared and Raman. In the calculation of species $A_{1}$ a correlation is found to all except one of the polarized Raman frequencies.
\end{abstract}

\section{Introduction}

The heptamolybdate anion $\mathrm{Mo}_{7} \mathrm{O}_{24}{ }^{6-}$ is well established in both the solid state and aqueous solution $[1-4]$, and a great number of experimental vibrational spectra is reported [5-11].

The assignments of the infrared and Raman spectra are incomplete $[10-11]$, since sufficient experimental data are mostly not available for such large complexes. There is thus need for a theoretical treatment which can increase the knowledge of the vibrational features. No normal coordinates analysis for the whole heptamolybdate anion has been published so far.

In the present work a successful analysis of symmetry coordinates was achieved for the $\mathrm{Mo}_{7} \mathrm{O}_{24}$ group. The analysis was difficult due to the very condensed structure, until the idea of treating fragments of the molecule as separate units was applied.

The method was originally used by Cyvin et al. for some metal-ligand complexes [12-13] and has later proved to be successful even for complexes where the ligand concept is chemically inadequate [14-16].

The word ligand will be used sometimes in accordance with the earlier terminology, even if the word fragment is more adequate.

Reprint request to be sent to Lennart Lyhamn, Department of Inorganic Chemistry, University of Umeå, S-901 87 Umeå, Sweden.

0340-4811/ 79 / 0700-0867\$01.00/0

\section{Theory}

The heptamolybdate anion is assumed to have a $\mathrm{C}_{2 \mathrm{v}}$ symmetry. This assumption agrees closely with the $\mathrm{X}$-ray structure determination [1]. A central framework $\mathrm{MoO}_{2}$ is assumed to have four ligands of two different types. There are thus two ligands $(\mathrm{A}, \mathrm{B})$ of each type, $\mathrm{L} 1$ and $\mathrm{L} 2$, respectively. The type labelled $\mathrm{L} 1$ is a $\mathrm{MoO}_{5}$ fragment having a $\mathrm{C}_{\mathrm{s}}(y z)$ symmetry, and the other type L2 is a $\mathrm{Mo}_{2} \mathrm{O}_{6}$ fragment having a $\mathrm{C}_{\mathrm{s}}(x z)$ symmetry. The vibrational modes are then classified into (a) framework vibrations, $F$, (b) ligand vibrations of two types; L1 and L2, (c) framework-ligand couplings of two types; F-L 1 and F-L2, and (d) interligand vibrations, L1-L2. This is an extension from the original work [12-13], where only one type of ligand was at the hand.

\section{Molecular and Fragmental Models}

A schematic figure of a $\mathrm{Mo}_{7} \mathrm{O}_{24}$ unit is shown in Fig. 1a. The symmetry is assumed to be $\mathrm{C}_{2 \mathrm{v}}$. The cartesian coordinates were deduced on the basis of single crystal data [1], and values of bond lengths are shown in the upper left part of Figure $1 \mathrm{~b}$. The geometrical parameters for a certain symmetrically equivalent set are means of the experimental values belonging to the specific set. The numbering and the structures of the framework, ligand L $1 \mathrm{~A}$ and ligand L2 A, are shown in Figs. 2, 3 and 5, respectively. The bonds involved in coupling coordinates are dotted. A key for the numbering and identification of the atoms is given in Table 1 . 

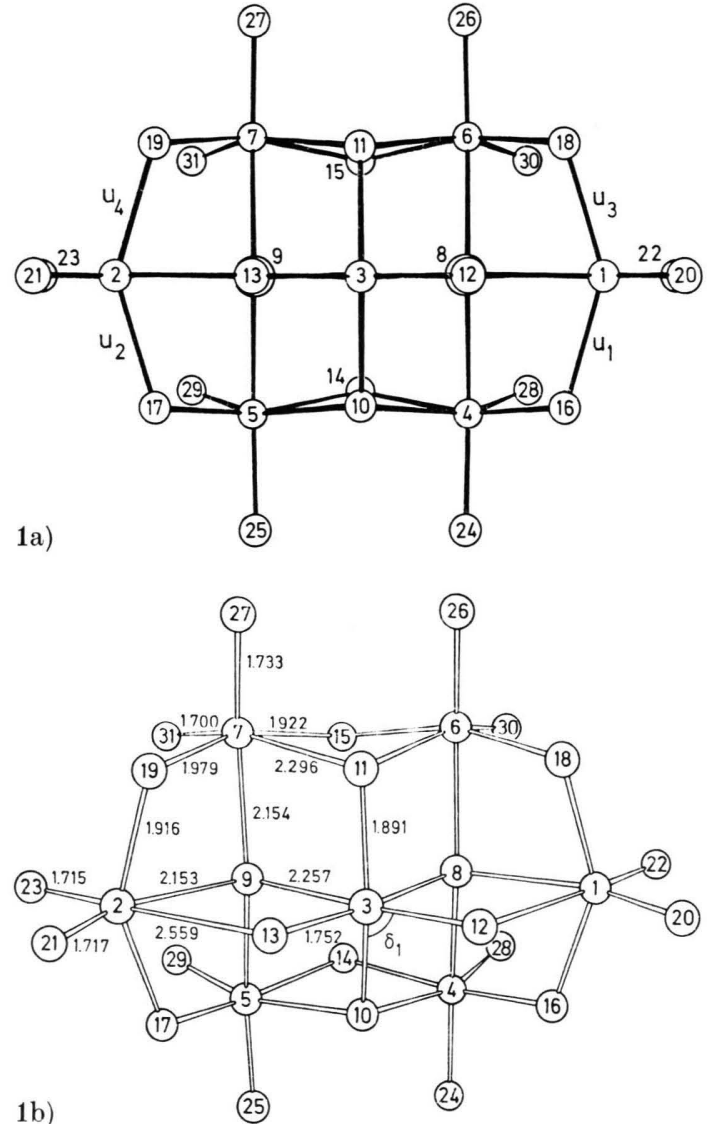

Fig. 1. a) A top view of the $\mathrm{Mo}_{7} \mathrm{O}_{24}$ model. b) The $\mathrm{Mo}_{7} \mathrm{O}_{24}$ structure, with the bond lengths in $\AA$.

The oxygen atoms 12 and 13 (Fig. 2) were decided to belong to the framework instead of the atoms 8 and 9 (Figs. 2, 3) due to the shorter bond lengths, $\sim 1.75 \AA$ vs. $\sim 2.25 \AA$. Furthermore, it seems more suitable that atom 8 belongs to the ligand $\mathrm{L} 1 \mathrm{~A}$ instead of atom 12 , also on the basis of bond lengths which are $\sim 2.15 \AA$ and $\sim 2.55 \AA$, respectively.

Table 1. Numbering of the atoms in the $\mathrm{Mo}_{7} \mathrm{O}_{24}$ unit, arranged according to the different fragments; $\mathrm{O}_{t}=$ terminal oxygens.

\begin{tabular}{|c|c|c|c|c|c|}
\hline \multirow{2}{*}{$\frac{\text { Fragment }}{\text { Atom }}$} & \multirow{2}{*}{$\begin{array}{l}\mathrm{MoO}_{2} \\
\mathrm{~F}\end{array}$} & \multicolumn{2}{|l|}{$\mathrm{MoO}_{5}$} & \multicolumn{2}{|l|}{$\mathrm{Mo}_{2} \mathrm{O}_{6}$} \\
\hline & & L1A & L1B & $\mathrm{L} 2 \mathrm{~A}$ & $\mathrm{~L} 2 \mathrm{~B}$ \\
\hline Мо & 3 & 1 & 2 & $4, \tilde{5}$ & 6,7 \\
\hline $\mathrm{O}$ & 12,13 & $\begin{array}{l}8 \\
16,18\end{array}$ & $\stackrel{9}{17,19}$ & $\begin{array}{l}10 \\
14\end{array}$ & $\begin{array}{l}11 \\
15\end{array}$ \\
\hline $\mathrm{O}_{\mathrm{t}}$ & & 20,22 & 21,23 & $\begin{array}{l}24,25 \\
28,29\end{array}$ & $\begin{array}{l}26,27 \\
30,31\end{array}$ \\
\hline
\end{tabular}

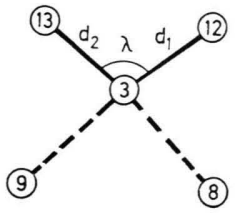

Fig. 2. $\mathrm{MoO}_{4}$ part of the $\mathrm{Mo}_{7} \mathrm{O}_{24}$ model showing the $\mathrm{MoO}_{2}$ (F) fragment; symmetry $\mathrm{C}_{2 \mathrm{v}}$ (Couplings dashed lines.)

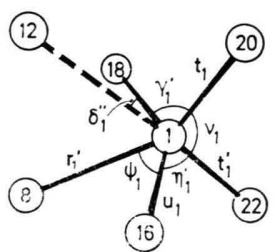

Fig. 3. A $\mathrm{MoO}_{6}$ part of the $\mathrm{Mo}_{7} \mathrm{O}_{24}$ model, showing the $\mathrm{MoO}_{5}(\mathrm{~L} 1 \mathrm{~A})$ fragment; symmetry $\mathrm{C}_{\mathrm{s}}(y z)$.

\section{Valence Coordinates}

(a) Framework Vibrations (F)

For the framework $\mathrm{MoO}_{2}$ the valence coordinates, $d$ and $\lambda$, are defined in Figure 2 .

\section{(b) Ligand Vibrations (L1, L2)}

L 1: For the ligand $\mathrm{MoO}_{5}(\mathrm{~L} 1 \mathrm{~A})$ the stretching $\left(r^{\prime}, u, t, t^{\prime}\right)$ and bending $\left(\gamma^{\prime}, \eta^{\prime}, \psi, v\right)$ coordinates are illustrated in Figure 3. The bending $\eta$ is shown in Fig. 4, where the two coplanar rings formed by the two L1 ligands and the framework are also illustrated. The order of numbering is that for the $u$ coordinate, shown in Fig. 1a, i.e. the ligand A corresponds always with odd numbers.

L2: The stretching $\left(u^{\prime \prime}, s, t^{\prime \prime}, t^{\prime \prime \prime}\right)$ and bending $\left(\omega, \omega^{\prime}, \zeta, \eta^{\prime \prime \prime}, \varepsilon, v^{\prime}, \gamma^{\prime \prime \prime}\right)$ coordinates for the ligand $\mathrm{Mo}_{2} \mathrm{O}_{6}$ (L2 A) are shown in Figure 5. For the two ligands L2 (A, B) we have also defined four torsions $o$, with the numbering $o_{1}$ (14-5-10-4), $o_{2}$ (14-4-10-5) for L2 A and analogously $o_{3}$ and $o_{4}$ for L 2 B.

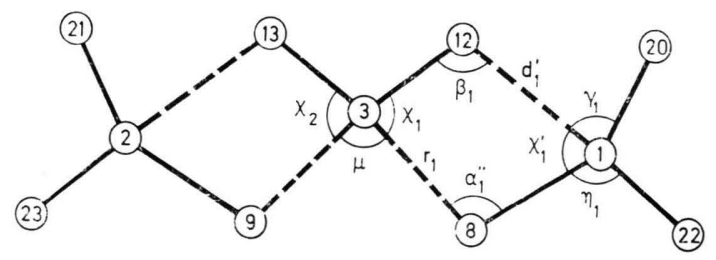

Fig. 4. The coplanar $\mathrm{Mo}_{2} \mathrm{O}_{2}$ rings made up from the couplings of the $\mathrm{F}$ and $\mathrm{L} 1$ fragments. 


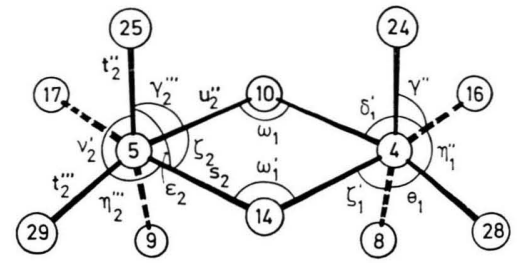

Fig. 5. A $\mathrm{Mo}_{2} \mathrm{O}_{10}$ part of the $\mathrm{Mo}_{7} \mathrm{O}_{24}$ model, showing the $\mathrm{Mo}_{2} \mathrm{O}_{6}$ (L2A) fragment; symmetry $\mathrm{C}_{\mathrm{S}}(x z)$.

\section{(c) Framework Ligand Couplings (F-L1-L2)}

(i) For the stretch coupling F-L 1 the coordinates $r, d^{\prime}$ are shown in Figure 4. The bendings $\alpha^{\prime \prime}, \beta, \gamma$, $\mu, \chi$ and $\chi^{\prime}$ for the planar $\mathrm{Mo}_{2} \mathrm{O}_{2}$ ring are also illustrated in Fig. 4, and $\delta^{\prime \prime}$ in Figure 3. In addition two torsions are defined, viz. $\tau_{1}(1-8-3-9)$ and $\tau_{2}(2-9-3-8)$.

(ii) For the coupling F-L2 the stretching $d^{\prime \prime}$ and bending $\beta^{\prime \prime}$ is shown in Fig. 6 , the bending $\delta$ is illustrated in Figure $1 \mathrm{~b}$. Here we have defined four torsions, $\tau^{\prime} ; \quad \tau_{1}{ }^{\prime}$ (4-10-3-13), $\tau_{2}{ }^{\prime}$ (5-10-3-12), $\tau_{3}{ }^{\prime}$ (6-11-3-13) and $\tau_{4}{ }^{\prime}(7-11-3-12)$, see Figure $1 \mathrm{~b}$.

(iii) Couplings F-L1-L2 in which both of the ligands take part are the bendings $\alpha^{\prime}$ and $\chi^{\prime \prime}$, which are shown in Figure 6 . We have in addition defined 6 torsions $\mathrm{p}$ for each of the four puckered $\mathrm{Mo}_{3} \mathrm{O}_{3}$ rings. For the F-L 1 A-L $2 \mathrm{~A}$ coupling the notation is $p_{1} \quad(16-1-12-3), \quad p_{2} \quad(1-12-3-10), \quad p_{3} \quad(12-3-10-4)$, $p_{4}(3-10-4-16), p_{5}(10-4-16-1)$ and $p_{6}(4-16-1-12)$ etc. for the other 18 torsions.

\section{(d) Interligand Vibrations (L1-L2)}

The interligand couplings are supposed to be important in this case. The condensed structure will lead to a great number of such couplings, which in turn give a stiffness to the structure. The

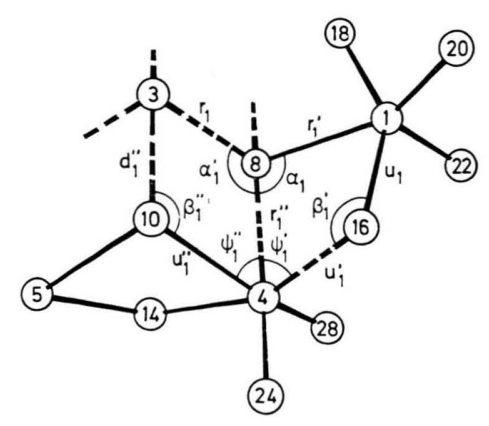

Fig. 6. A fragment of the $\mathrm{Mo}_{7} \mathrm{O}_{24}$ model showing the couplings F-L1, F-L2 and L1-L2. $\chi_{1}^{\prime \prime}$ is the $\wedge 10-3-8$. stretchings $u_{1}{ }^{\prime}$ and $r_{1}{ }^{\prime \prime}$ are shown in Figure 6 . The numbering follows that for $u$. The bendings $\gamma^{\prime \prime}, \delta^{\prime}$, $\zeta^{\prime}, \eta^{\prime \prime}$ and $\theta$ are shown in Fig. 5 and the bendings $\alpha$, $\beta^{\prime}, \psi^{\prime}$ and $\psi^{\prime \prime}$ in Figure 6 . We have in addition defined 8 torsions $\tau^{\prime \prime}$ for the four-membered $\mathrm{Mo}_{2} \mathrm{O}_{2}$ rings, formed by the bonds denoted $u, u^{\prime}, r^{\prime \prime}$ and $r^{\prime}$ shown in Figure 6 . There are four such rings and two torsions are constructed for each ring in the same manner as the torsion $o$, i.e. $\tau_{1}{ }^{\prime \prime}(16-1-8-4)$ and $\tau_{2}^{\prime \prime}(16-4-8-1)$ for example.

\section{Classification and Symmetry of the Normal Modes}

The whole complex of 31 atoms has 87 normal modes of vibration, which are distributed into the different species of the $\mathrm{C}_{2 \mathrm{v}}$ group according to

$$
\begin{aligned}
\Gamma\left(\mathrm{M}_{7} \mathrm{O}_{24}\right)= & 26 A_{1}(\mathrm{IR}, \mathrm{R})+18 A_{2}(\mathrm{R}) \quad(1) \\
& +20 B_{1}(\mathrm{IR}, \mathrm{R})+23 B_{2}(\mathrm{IR}, \mathrm{R}) .
\end{aligned}
$$

As mentioned, the $\mathrm{Mo}_{7} \mathrm{O}_{24}$ unit is divided into different fragments, and the normal modes of vibration for each of the fragments have to be derived.

(a) For the framework $\mathrm{MoO}_{2}$, which has a $\mathrm{C}_{2 \mathrm{v}}$ symmetry, the species are

$$
\Gamma\left(\mathrm{MoO}_{2}\right)=2 A_{1}+1 B_{2} .
$$

(b) The ligand $\mathrm{MoO}_{5}(\mathrm{~L} 1)$ has a $\mathrm{C}_{\mathrm{s}}(y z)$ symmetry, and the 12 normal modes of vibration are distributed into the species according to

$$
\Gamma\left(\mathrm{MoO}_{5}\right)=8 a^{\prime}+4 a^{\prime \prime} .
$$

The two ligands $\mathrm{L} 1$ and the correlation between the symmetry species of the $\mathrm{C}_{\mathrm{s}}(y z)$ and $\mathrm{C}_{2 \mathrm{v}}$ groups [17] (cf. Table 2) gives the following $\mathrm{C}_{2 \mathrm{v}}$ representation

$$
\Gamma(\mathrm{L} 1)=8 A_{1}+4 A_{2}+4 B_{1}+8 B_{2} .
$$

For the ligand $\mathrm{Mo}_{2} \mathrm{O}_{6}(\mathrm{~L} 2)$ the 18 normal modes of vibration are distributed into the following species of the $\mathrm{C}_{\mathrm{S}}(x z)$ group

$$
\Gamma\left(\mathrm{Mo}_{2} \mathrm{O}_{6}\right)=10 a^{\prime}+8 a^{\prime \prime} .
$$

Table 2. Correlation table for the species of the $\mathrm{C}_{2 \mathrm{v}}$ group and its subgroups $\mathrm{C}_{\mathrm{S}}(x z)$ and $\mathrm{C}_{\mathrm{S}}(y z)^{17}$.

\begin{tabular}{lllll}
\hline $\mathrm{C}_{2 \mathrm{v}}$ & $A_{1}$ & $A_{2}$ & $B_{1}$ & $B_{2}$ \\
$\mathrm{C}_{\mathrm{S}}(y z)$ & $a^{\prime}$ & $a^{\prime \prime}$ & $a^{\prime \prime}$ & $a^{\prime}$ \\
$\mathrm{C}_{\mathrm{S}}(x z)$ & $a^{\prime}$ & $a^{\prime \prime}$ & $a^{\prime}$ & $a^{\prime \prime}$ \\
\hline
\end{tabular}


A transformation of the species into the $\mathrm{C}_{2 \mathrm{v}}$ group (cf. Table 2) for two ligands gives the representation

$$
\Gamma(\mathrm{L} 2)=10 A_{1}+8 A_{2}+10 B_{1}+8 B_{2} .
$$

The total number of vibrational modes for the framework and all the ligands L 1 and L 2 is thus the sum of Eqs. (2), (4) and (6), which is

$$
\begin{aligned}
& \Gamma(\mathrm{F}, \mathrm{L} 1, \mathrm{~L} 2) \\
& \quad=20 A_{1}+12 A_{2}+14 B_{1}+17 B_{2} .
\end{aligned}
$$

The difference between Eqs. (1) and (7) is

$$
\Gamma=6 A_{1}+6 A_{2}+6 B_{1}+6 B_{2} .
$$

(c, d) Equation (8) gives totally 24 normal modes of vibration which are classified as different types of couplings. The distribution of the six modes for each species, Eq. (8), is made in such an even manner as possible, see Table 3 . Moreover, the pattern shall be so that the correlations in Table 2 remain valid. The F-L 1 couplings shall have about half the number of modes in species $A_{2}$ and $B_{1}$ compared with those in species $A_{1}$ and $B_{2}$, cf. Equation (4). These considerations give the distribution shown in Table 3 .

\section{Symmetry Coordinates}

The symmetry coordinates for the whole $\mathrm{Mo}_{7} \mathrm{O}_{24}{ }^{6-}$ complex are constructed by means of the intermediate coordinates for the individual fragments $\mathrm{F}, \mathrm{L} 1$ and $\mathrm{L} 2$.

Table 3 shows the correlations between the overall symmetry coordinates under the symmetry group $\mathrm{C}_{2 \mathrm{v}}$ and those of the ligand and coupling vibrations.

Table 3. Classification of the normal modes and a compilation of the correlation for the species of the groups $\mathrm{C}_{\mathrm{S}}$ and $\mathrm{C}_{2 \mathrm{v}}$.

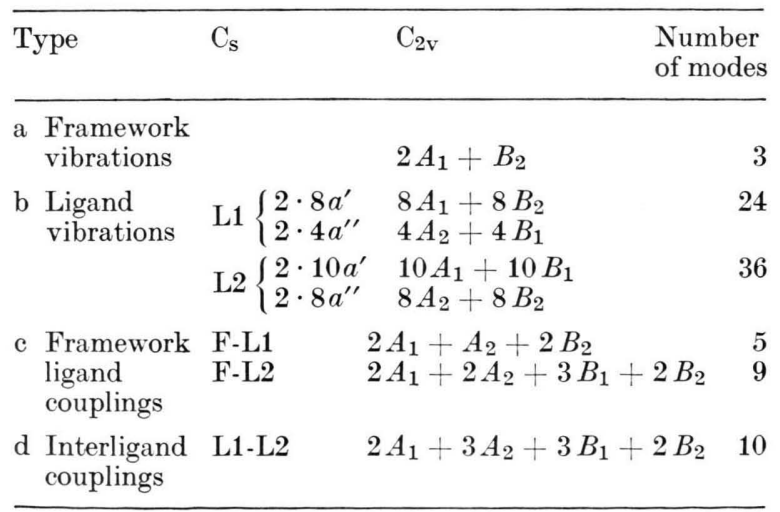

The 87 symmetry coordinates are constructed out of 30 internal coordinates. All of the 87 symmetry coordinates are not given explicitely, although most of them are included. A compilation of the chosen coordinates and of the distribution into different species in the $\mathrm{C}_{2 \mathrm{v}}$ group is given in Table 4 .

The $\mathrm{MoO}_{2}$ unit. The two valence coordinates $d$ and $\lambda$ take part in the symmetry coordinates given below,

$$
\begin{aligned}
& S_{1}\left(A_{1}\right)=2^{-1 / 2}\left(d_{1}+d_{2}\right), \\
& S_{2}\left(A_{1}\right)=D \cdot \lambda, \\
& S_{1}\left(B_{2}\right)=2^{-1 / 2}\left(d_{1}-d_{2}\right) .
\end{aligned}
$$

\begin{tabular}{|c|c|c|c|c|c|}
\hline \multirow[b]{2}{*}{ Type } & \multicolumn{4}{|c|}{ Species } & \\
\hline & $A_{1}$ & $A_{2}$ & $B_{1}$ & $B_{2}$ & \\
\hline $\begin{array}{l}d \\
\lambda\end{array}$ & $\begin{array}{l}+ \\
+\end{array}$ & & & $+\}$ & F \\
\hline $\begin{array}{l}u \\
r^{\prime} \\
t\end{array}$ & $\begin{array}{l}+ \\
+ \\
+\end{array}$ & + & + & $\begin{array}{l}+ \\
+ \\
+\end{array}$ & \\
\hline$t^{\prime}$ & $\begin{array}{l}+ \\
+\end{array}$ & + & + & $\begin{array}{l}+ \\
+\end{array}$ & L1 \\
\hline $\begin{array}{l}\eta^{\prime} \\
v\end{array}$ & + & + & + & + & \\
\hline$\psi$ & + & + & + & $+J$ & \\
\hline$u^{\prime \prime}$ & + & + & + & + & \\
\hline $\begin{array}{l}s \\
t^{\prime \prime}\end{array}$ & + & + & + & $\begin{array}{l}+ \\
+\end{array}$ & \\
\hline$t^{\prime \prime \prime}$ & + & + & + & + & \\
\hline $\begin{array}{l}\gamma^{\prime \prime \prime \prime} \\
\varepsilon\end{array}$ & + & + & $\begin{array}{l}+ \\
+\end{array}$ & + & L2 \\
\hline$v^{\prime}$ & + & + & + & + & \\
\hline $\begin{array}{l}\omega \\
\eta^{\prime \prime \prime} \\
\text { o }\end{array}$ & $\begin{array}{l}+ \\
+ \\
+\end{array}$ & + & $\begin{array}{l}+ \\
+ \\
+\end{array}$ & +1 & \\
\hline $\begin{array}{r}r \\
d^{\prime}\end{array}$ & + & & & +1 & F I \\
\hline$\tau$ & † & + & & + & $\Gamma-L 1$ \\
\hline $\begin{array}{l}d^{\prime \prime} \\
\beta^{\prime \prime}\end{array}$ & $\begin{array}{l}+ \\
+\end{array}$ & + & $\begin{array}{l}+ \\
+\end{array}$ & + & F-L2 \\
\hline$\tau^{\prime}$ & & + & + & $+J$ & \\
\hline $\begin{array}{l}u^{\prime} \\
\gamma^{\prime \prime}\end{array}$ & + & + & + & +1 & L1-L2 \\
\hline$\tau^{\prime \prime}$ & & + & + & & \\
\hline & 26 & 18 & 20 & 23 & \\
\hline
\end{tabular}

The $\mathrm{MoO}_{5}$ unit. The $24(2 \cdot 12)$ symmetry coordinates [Eqs. (3), (4)] for the two $\mathrm{MoO}_{5}$ units were constructed in the following way;

$$
\begin{aligned}
& S_{3}\left(A_{1}\right)=\frac{1}{2}\left(u_{1}+u_{2}+u_{3}+u_{4}\right), \\
& S_{4}\left(A_{1}\right)=2^{-1 / 2}\left(r_{1}{ }^{\prime}+r_{2}{ }^{\prime}\right),
\end{aligned}
$$

Table 4. A compilation of the basic set of symmetry coordinates and their occurance in the different species. 


$$
\begin{aligned}
& S_{5}\left(A_{1}\right)=2^{-1 / 2}\left(t_{1}+t_{2}\right), \\
& S_{6}\left(A_{1}\right)=2^{-1 / 2}\left(t_{1}{ }^{\prime}+t_{2}{ }^{\prime}\right), \\
& S_{7}\left(A_{1}\right)=\frac{1}{2}(T U)^{1 / 2}\left(\gamma_{1}{ }^{\prime}+\gamma_{2}{ }^{\prime}+\gamma_{3}{ }^{\prime}+\gamma_{4}{ }^{\prime}\right), \\
& S_{8}\left(A_{1}\right)=\frac{1}{2}\left(T^{\prime} U\right)^{1 / 2}\left(\eta_{1}{ }^{\prime}+\eta_{2}{ }^{\prime}+\eta_{3}{ }^{\prime}+\eta_{4}{ }^{\prime}\right), \\
& S_{9}\left(A_{1}\right)=\frac{1}{2}\left(R^{\prime} U\right)^{1 / 2}\left(\psi_{1}+\psi_{2}+\psi_{3}+\psi_{4}\right), \\
& S_{10}\left(A_{1}\right)=\left(T T^{\prime} / 2\right)^{1 / 2}\left(\nu_{1}+\nu_{2}\right), \\
& S_{1}\left(A_{2}\right)=\frac{1}{2}\left(u_{1}-u_{2}-u_{3}+u_{4}\right), \\
& S_{2}\left(A_{2}\right)=\frac{1}{2}(T U)^{1 / 2}\left(\gamma_{1}{ }^{\prime}-\gamma_{2}{ }^{\prime}-\gamma_{3}{ }^{\prime}+\gamma_{4}{ }^{\prime}\right), \\
& S_{3}\left(A_{2}\right)=\frac{1}{2}\left(T^{\prime} U\right)^{1 / 2}\left(\eta_{1}{ }^{\prime}-\eta_{2}{ }^{\prime}-\eta_{3}{ }^{\prime}+\eta_{4}{ }^{\prime}\right), \\
& S_{4}\left(A_{2}\right)=\frac{1}{2}\left(R^{\prime} U\right)^{1 / 2}\left(\psi_{1}-\psi_{2}-\psi_{3}-\psi_{4}\right) .
\end{aligned}
$$

The $u$ coordinate is used to show the pattern in the $B_{1}$ and $B_{2}$ species, i.e.;

$$
\begin{aligned}
& S_{1}\left(B_{1}\right)=\frac{1}{2}\left(u_{1}+u_{2}-u_{3}-u_{4}\right), \\
& S_{2}\left(B_{2}\right)=\frac{1}{2}\left(u_{1}-u_{2}+u_{3}-u_{4}\right),
\end{aligned}
$$

The symmetry coordinates $S_{2}\left(B_{1}\right)-S_{4}\left(B_{1}\right)$ and $S_{7}\left(B_{2}\right)-S_{9}\left(B_{2}\right)$ for $\gamma^{\prime}, \eta^{\prime}$ and $\psi$ are constructed in the same manner.

In addition the $r^{\prime}, t, t^{\prime}$ and $v$ coordinates are represented in the $B_{2}$ species, $S_{3}\left(B_{2}\right)-S_{6}\left(B_{2}\right)$ (cf. Table 4); for example $S_{3}\left(B_{2}\right)=2^{-1 / 2}\left(r_{1}{ }^{\prime}-r_{2}{ }^{\prime}\right)$.

The $\mathrm{Mo}_{2} \mathrm{O}_{6}$ unit. The $36 \quad(2 \cdot 18)$ symmetry coordinates [Eqs. (5), (6)] for the two $\mathrm{Mo}_{2} \mathrm{O}_{6}$ units were constructed in the following way:

$$
\begin{aligned}
& S_{11}\left(A_{1}\right)=\frac{1}{2}\left(u_{1}{ }^{\prime \prime}+u_{2}{ }^{\prime \prime}+u_{3}{ }^{\prime \prime}+u_{4}{ }^{\prime \prime}\right) \text {, } \\
& S_{12}\left(A_{1}\right)=\frac{1}{2}\left(s_{1}+s_{2}+s_{3}+s_{4}\right) \text {, } \\
& S_{13}\left(A_{1}\right)=\frac{1}{2}\left(t_{1}{ }^{\prime \prime}+t_{2}{ }^{\prime \prime}+t_{3}{ }^{\prime \prime}+t_{4}{ }^{\prime \prime}\right) \text {, } \\
& S_{14}\left(A_{1}\right)=\frac{1}{2}\left(t_{1}{ }^{\prime \prime \prime}+t_{2}{ }^{\prime \prime \prime}+t_{3}{ }^{\prime \prime \prime}+t_{4}{ }^{\prime \prime \prime}\right) \text {, } \\
& S_{15}\left(A_{1}\right)=\frac{1}{2}\left(S T^{\prime \prime}\right)^{1 / 2}\left(\varepsilon_{1}+\varepsilon_{2}+\varepsilon_{3}+\varepsilon_{4}\right) \text {, } \\
& S_{16}\left(A_{1}\right)=\frac{1}{2}\left(T^{\prime \prime} U^{\prime \prime}\right)^{1 / 2}\left(\gamma_{1}{ }^{\prime \prime}+\gamma_{2}{ }^{\prime \prime \prime}+\gamma_{3}{ }^{\prime \prime \prime}+\gamma_{4}{ }^{\prime \prime \prime}\right) \text {, } \\
& S_{17}\left(A_{1}\right)=\frac{1}{2}\left(T^{\prime \prime} T^{\prime \prime \prime}\right)^{1 / 2}\left(\nu_{1}{ }^{\prime}+\nu_{2}{ }^{\prime}+\nu_{3}{ }^{\prime}+\nu_{4}{ }^{\prime}\right) \text {, } \\
& S_{18}\left(A_{1}\right)=2^{-1 / 2} U^{\prime \prime}\left(\omega_{1}+\omega_{2}\right) \text {, } \\
& S_{19}\left(A_{1}\right)=\frac{1}{2}\left(S T^{\prime \prime \prime}\right)^{1 / 2}\left(\eta_{1}{ }^{\prime \prime \prime}+\eta_{2}{ }^{\prime \prime \prime}+\eta_{3}{ }^{\prime \prime \prime}+\eta_{4}{ }^{\prime \prime \prime}\right) \text {, } \\
& S_{20}\left(A_{1}\right)=\frac{1}{2}\left(S U^{\prime \prime}\right)^{1 / 2}\left(o_{1}-o_{2}+o_{3}-o_{4}\right), \\
& S_{5}\left(A_{2}\right)=\frac{1}{2}\left(u_{1}^{\prime \prime}-u_{2}{ }^{\prime \prime}-u_{3}{ }^{\prime \prime}+u_{4}{ }^{\prime \prime}\right) \text {, } \\
& S_{6}\left(A_{2}\right)=\frac{1}{2}\left(s_{1}-s_{2}-s_{3}+s_{4}\right) \text {, } \\
& S_{7}\left(A_{2}\right)=\frac{1}{2}\left(t_{1}{ }^{\prime \prime}-t_{2}{ }^{\prime \prime}-t_{3}{ }^{\prime \prime}+t_{4}{ }^{\prime \prime}\right) \text {, } \\
& S_{8}\left(A_{2}\right)=\frac{1}{2}\left(t_{1}{ }^{\prime \prime \prime}-t_{2}{ }^{\prime \prime}-t_{3}{ }^{\prime \prime \prime}+t_{4}{ }^{\prime \prime \prime}\right) \text {, } \\
& S_{9}\left(A_{2}\right)=\frac{1}{2}\left(S T^{\prime \prime}\right)^{1 / 2}\left(\varepsilon_{1}-\varepsilon_{2}-\varepsilon_{3}+\varepsilon_{4}\right) \text {, } \\
& S_{10}\left(A_{2}\right)=\frac{1}{2}\left(T^{\prime \prime} U^{\prime \prime}\right)^{1 / 2}\left(\gamma_{1}{ }^{\prime \prime \prime}-\gamma_{2}{ }^{\prime \prime \prime}-\gamma_{3}{ }^{\prime \prime \prime}+\gamma_{4}{ }^{\prime \prime \prime}\right) \text {, } \\
& S_{11}\left(A_{2}\right)=\frac{1}{2}\left(T^{\prime \prime} T^{\prime \prime \prime}\right)^{1 / 2}\left(\nu_{1}{ }^{\prime}-\nu_{2}{ }^{\prime}-\nu_{3}{ }^{\prime}+\nu_{4}{ }^{\prime}\right) \text {, } \\
& S_{12}\left(A_{2}\right)=\frac{1}{2}\left(S T^{\prime \prime \prime}\right)^{1 / 2}\left(\eta_{1}{ }^{\prime \prime \prime}-\eta_{2}{ }^{\prime \prime \prime}-\eta_{3}{ }^{\prime \prime \prime}+\eta_{4}{ }^{\prime \prime \prime}\right) \text {. }
\end{aligned}
$$

The same valence coordinates as used in $A_{1}(11-20)$ are used for $S_{5}\left(B_{1}\right)-S_{14}\left(B_{1}\right)$, and those in $A_{2}(5-12)$ are used for $S_{10}\left(B_{2}\right)-S_{17}\left(B_{2}\right)$, cf. Table 4 . The expression may be derived from the $u^{\prime \prime}$ examples given below,

$$
\begin{aligned}
& S_{5}\left(B_{1}\right)=\frac{1}{2}\left(u_{1}{ }^{\prime \prime}+u_{2}{ }^{\prime \prime}-u_{3}{ }^{\prime \prime}-u_{4}{ }^{\prime \prime}\right), \\
& S_{9}\left(B_{2}\right)=\frac{1}{2}\left(u_{1}{ }^{\prime \prime}-u_{2}{ }^{\prime \prime}+u_{3}{ }^{\prime \prime}-u_{4}{ }^{\prime \prime}\right) .
\end{aligned}
$$

The $S_{14}\left(B_{1}\right)$ coordinates shall contain the torsions $o$ which are written in the following way;

$$
S_{14}\left(B_{1}\right)=\frac{1}{2}\left(S U^{\prime \prime}\right)^{1 / 2}\left(o_{1}-o_{2}-o_{3}+o_{4}\right) .
$$

Coupling and interligand vibrations. There are 6 symmetry coordinates for coupling and interligand vibrations for each of the species $A_{1}, A_{2}, B_{1}$ and $B_{2}$, Equation (8).

The number of each category (F-L1, F-L2, L1-L2) and the type of valence coordinates are illustrated in Table 4. These coordinates are combined in the following way:

$$
\begin{aligned}
& S_{21}\left(A_{1}\right)=2^{-1 / 2}\left(r_{1}+r_{2}\right), \\
& S_{22}\left(A_{1}\right)=2^{-1 / 2}\left(d_{1}{ }^{\prime}+d_{2}{ }^{\prime}\right), \\
& S_{23}\left(A_{1}\right)=2^{-1 / 2}\left(d_{1}{ }^{\prime \prime}+d_{2}{ }^{\prime \prime}\right), \\
& S_{24}\left(A_{1}\right)=\frac{1}{2}\left(D^{\prime \prime} U^{\prime \prime}\right)^{1 / 2}\left(\beta_{1}{ }^{\prime \prime}+\beta_{2}{ }^{\prime \prime}+\beta_{3}{ }^{\prime \prime}+\beta_{4}{ }^{\prime \prime}\right), \\
& S_{25}\left(A_{1}\right)=\frac{1}{2}\left(u_{1}{ }^{\prime}+u_{2}{ }^{\prime}+u_{3}{ }^{\prime}+u_{4}{ }^{\prime}\right), \\
& S_{26}\left(A_{1}\right)=\frac{1}{2}\left(T^{\prime \prime} U^{\prime}\right)^{1 / 2}\left(\gamma_{1}{ }^{\prime \prime}+\gamma_{2}{ }^{\prime \prime}+\gamma_{3}{ }^{\prime \prime}+\gamma_{4}{ }^{\prime \prime}\right) .
\end{aligned}
$$

The combination for the other species is the same as for $u^{\prime \prime}$, and will therefore not be given. The torsions $\tau, \tau^{\prime}$ and $\tau^{\prime \prime}$ are not so easily combined and these symmetry coordinates are given below:

$$
\begin{aligned}
& S_{13}\left(A_{2}\right)=\left(D D^{\prime} / 2\right)^{1 / 2}\left(\tau_{1}+\tau_{2}\right), \\
& S_{15}\left(A_{2}\right)=\frac{1}{2}\left(D U^{\prime \prime}\right)^{1 / 2}\left(\tau_{1}{ }^{\prime}+\tau_{2}{ }^{\prime}+\tau_{3}{ }^{\prime}+\tau_{4}{ }^{\prime}\right), \\
& S_{18}\left(A_{2}\right)=N\left(\tau_{1}{ }^{\prime \prime}-\tau_{2}{ }^{\prime \prime}+\tau_{3}{ }^{\prime \prime}-\tau_{4}{ }^{\prime \prime}\right. \\
& \left.\quad+\tau_{5}{ }^{\prime \prime}-\tau_{6}{ }^{\prime \prime}+\tau_{7}{ }^{\prime \prime}-\tau_{8}{ }^{\prime \prime}\right), \\
& S_{15}\left(B_{1}\right)=\left(D D^{\prime} / 2\right)^{1 / 2}\left(\tau_{1}-\tau_{2}\right), \\
& S_{20}\left(B_{1}\right)=N\left(\tau_{1}{ }^{\prime \prime}-\tau_{2}{ }^{\prime \prime}-\tau_{3}{ }^{\prime \prime}+\tau_{4}{ }^{\prime \prime}\right. \\
& \left.\quad+\tau_{5}^{\prime \prime}-\tau_{6}{ }^{\prime \prime}-\tau_{7}{ }^{\prime \prime}+\tau_{8}{ }^{\prime \prime}\right), \\
& S_{21}\left(B_{2}\right)=\frac{1}{2}\left(D U^{\prime \prime}\right)^{1 / 2}\left(\tau^{\prime}+\tau_{2}{ }^{\prime}-\tau_{3}{ }^{\prime}-\tau_{4}{ }^{\prime}\right),
\end{aligned}
$$

where $N=\left(R^{\prime} R^{\prime \prime} U U^{\prime} / 8\right)^{1 / 2}$.

\section{Force Field Calculations}

A diagonal valence force constant matrix was used in all the presented calculations. Redundancies were, however, allowed and incorporated successively in a manner described below. The Mo-O stretching force constants were produced by means of the empirical correlations to bond lengths given by 
Cotton et al. [18]. In this valuation the experimental X-Ray values of the bond lengths were used instead of the mean values, because of the nonlinear relationship between the force constants and the atomic distances, $f_{\mathrm{Mo}-\mathrm{O}}=g\left(r_{\mathrm{Mo}-\mathrm{O}}\right)$. This emphasizes that the physical features are more important here than in the earlier geometrical treatment. For bending and torsional force constants there are no general or simple empirical formulas to use.

\section{Classification of Angles}

The angles $\mathrm{O}_{i}-\mathrm{Mo}-\mathrm{O}_{j}$ were divided into sets according to the number of bonds to the $\mathrm{O}_{i}$ atoms. The oxygens with the same $i$ value thus form a set where the other oxygens $\mathrm{O}_{j}$ have different $j$ values. so that $i \leqq j$; i.e. $j=i, i+1, i+2, \ldots$. There are thus four such sets as $1 \leqq i \leqq 4$. The force constants are increased within a set with increasing $j$ value, as well as between the sets with increasing $i$ value. The angles $\mathrm{Mo}-\mathrm{O}_{i}-\mathrm{Mo}$, where $i=2,3,4$, form a fifth set.

Such a relative scale makes an adjustment of the force constants easier and more relevant because a change in the values for one or several angles will then perhaps lead to adjustments of other force constants of related angles. As starting values for some preliminary calculations the values for the $\mathrm{PMo}_{12} \mathrm{O}_{40}^{3-}$ ion were used [15]. The final values for the angles are shown in Table 5. As seen in the table some angles assume values which differ from the others on the same line. This is due to the fact that the bonds involving the atoms 12 and 13

Table 5. Classification and valence force constants for the angles.

\begin{tabular}{|c|c|c|}
\hline Set & Type & $f / \operatorname{mdyn} \AA^{-1}$ \\
\hline 1. $\begin{aligned} & \mathrm{O}_{1}-\mathrm{Mo}-\mathrm{O}_{1} \\
&- \mathrm{O}_{2} \\
&-\mathrm{O}_{3} \\
&-\mathrm{O}_{4}\end{aligned}$ & $\begin{array}{l}v, v^{\prime} \\
\gamma ; \gamma^{\prime}, \gamma^{\prime \prime}, \varepsilon, \eta^{\prime}, \eta^{\prime \prime}, \eta^{\prime \prime \prime} \\
\gamma^{\prime \prime \prime} \\
\theta, \eta\end{array}$ & $\begin{array}{l}0.15 \\
0.20 ; 0.25 \\
0.27 \\
0.30\end{array}$ \\
\hline 2. $\begin{aligned} \mathrm{O}_{2}-\mathrm{Mo}-\mathrm{O}_{2} \\
-\mathrm{O}_{3} \\
-\mathrm{O}_{4}\end{aligned}$ & $\begin{array}{l}\delta^{\prime \prime} ; \lambda \\
\delta ; \delta^{\prime}, \zeta \\
\chi ; \chi^{\prime} ; \psi, \psi^{\prime}, \zeta^{\prime}\end{array}$ & $\begin{array}{l}0.27 ; 0.33 \\
0.33 ; 0.32 \\
0.36 ; 0.34 ; 0.35\end{array}$ \\
\hline 3. $\begin{array}{r}\mathrm{O}_{3}-\mathrm{Mo}-\mathrm{O}_{3} \\
-\mathrm{O}_{4}\end{array}$ & $\overline{\chi^{\prime \prime}}, \psi^{\prime \prime}$ & 0.38 \\
\hline 4. $\mathrm{O}_{4}-\mathrm{Mo}-\mathrm{O}_{4}$ & $\mu$ & 0.40 \\
\hline 5. Мo- $\begin{array}{r}\mathrm{O}_{2}-\mathrm{Mo} \\
-\mathrm{O}_{3-} \\
-\mathrm{O}_{4-}^{-}\end{array}$ & $\begin{array}{l}\beta, \beta^{\prime}, \omega^{\prime} \\
\beta^{\prime \prime}, \omega \\
\alpha, \alpha^{\prime}, \alpha^{\prime \prime}\end{array}$ & $\begin{array}{l}0.40 \\
0.42 \\
0.44\end{array}$ \\
\hline
\end{tabular}

Table 6. Calculated frequencies, $v / \mathrm{cm}^{-1}$, for the block $A_{1}$.

\begin{tabular}{rrrrrr}
\hline & \multicolumn{1}{l}{ I } & II & III & IV & V \\
\hline 1 & 951 & 954 & 954 & 957 & 958 \\
2 & 934 & 935 & 939 & 940 & 940 \\
3 & 902 & 903 & 912 & 913 & 917 \\
4 & 889 & 889 & 899 & 901 & 902 \\
5 & 857 & 857 & 889 & 894 & 895 \\
6 & 772 & 773 & 774 & 834 & 842 \\
7 & 756 & 760 & 760 & 772 & 818 \\
8 & 611 & 693 & 693 & 745 & 754 \\
9 & 537 & 580 & 661 & 699 & 717 \\
10 & 527 & 545 & 588 & 666 & 704 \\
11 & 500 & 501 & 567 & 657 & 676 \\
12 & 426 & 456 & 559 & 605 & 635 \\
13 & 399 & 407 & 522 & 553 & 554 \\
14 & 318 & 325 & 325 & 396 & 404 \\
15 & 258 & 278 & 312 & 390 & 396 \\
16 & 231 & 270 & 291 & 341 & 346 \\
17 & 206 & 235 & 279 & 299 & 303 \\
18 & 195 & 225 & 242 & 286 & 292 \\
19 & 184 & 198 & 232 & 257 & 271 \\
20 & 144 & 174 & 219 & 250 & 254 \\
21 & 134 & 149 & 176 & 230 & 231 \\
22 & 104 & 132 & 146 & 217 & 217 \\
23 & 89 & 108 & 139 & 177 & 181 \\
24 & 73 & 85 & 109 & 168 & 168 \\
25 & 54 & 68 & 96 & 122 & 127 \\
26 & 8 & 51 & 70 & 91 & 105 \\
\hline & & & & &
\end{tabular}

differ considerably in length from the rest on the same line. A separation of the angles and the corresponding values is made by a semicolon (;) in Table 5 .

\section{Redundants}

A stepwise introduction of redundants was only performed for species $A_{1}$ and the result is shown in Table 6. The result for the basic set, i.e. no redundants except the stretching $r^{\prime \prime}$, is shown in column I and the results including additional redundants in columns II $-\mathrm{V}$.

The angles for the ligands L1 and L2 were introduced as the first redundants (II). Then the couplings F-L 1 and F-L2 were incorporated (III), and then the couplings L1-L2 (IV), and finally different combinations of the F-L1-L2 and L1L2-L1 couplings (V). The torsions $\tau$ (F-L 1$)$ and $\tau^{\prime}(\mathrm{F}-\mathrm{L} 2)$ are introduced in the calculations III and the torsion $\tau^{\prime \prime}(\mathrm{L} 1-\mathrm{L} 2)$ in IV. All the torsions were given the force constant value 0.01 mdyn $\AA^{-1}$.

\section{Force Constants and Compliants}

The valance diagonal force constant matrix was converted to a standard $F$ matrix, i.e. symmetry 
force constants, and quite new values were obtained when redundants were incorporated. The diagonal terms, $F_{i i}$, are more interesting than the offdiagonal terms, so these are not discussed even if some of them are not small. There was no offdiagonal term greater than the greatest diagonal term. It must be noticed that only the whole block of the $F$ matrix has a physical meaning with reference to the particular set of symmetry coordinates. The $F_{i i}$ terms for the basic set (I) as well as including all redundants (II) are shown in Table 7 for species $A_{1}$. The values within parenthesis for the stretch coordinates are equal to the mean value of the set. The values for the angles and the torsions are equal within one symmetrical equivalent set. The change in the diagonal terms, $F_{i i}$, is large for some coordinates, ef. column I and II. The values for the terminal oxygens are, however, constant. The many high values cannot be interpreted as force constants for the related bendings, stretchings or torsions.

Table 7. The diagonal symmetry force constants, $F$ /mdyn $\AA^{-1}$ / and compliants, $N / \AA$ mdyn $^{-1}$ / for the species $A_{1}$, from two different calculations each. The values within parenthesis are means of the initial force constants.

\begin{tabular}{|c|c|c|c|c|c|}
\hline & & \multicolumn{2}{|c|}{$F_{i i} / \operatorname{mdyn} \AA^{-1} /$} & \multicolumn{2}{|c|}{$N_{i i} / \AA \operatorname{mdyn}^{-1} /$} \\
\hline & & I & II & III & IV \\
\hline$r \quad($ & $(1.310)$ & 1.585 & 4.995 & 0.763 & 0.373 \\
\hline$r^{\prime}$ & (1.925) & 2.029 & 5.805 & 0.519 & 0.315 \\
\hline$d$ & $(6.000)$ & 6.007 & 6.635 & 0.167 & 0.158 \\
\hline$d^{\prime}$ & $(0.830)$ & 0.941 & 2.574 & 1.205 & 0.688 \\
\hline$d^{\prime \prime}$ & $(4.125)$ & 9.718 & 37.797 & 0.242 & 0.200 \\
\hline$u$ & $(3.850)$ & 14.094 & 28.835 & 0.259 & 0.232 \\
\hline$u^{\prime}$ & $(3.225)$ & 3.596 & 6.556 & 0.310 & 0.276 \\
\hline$u^{\prime \prime}$ & $(1.288)$ & 1.627 & 6.732 & 0.776 & 0.445 \\
\hline$s \quad($ & (3.773) & 3.838 & 7.835 & 0.265 & 0.225 \\
\hline$t$ & $(6.675)$ & 6.675 & 6.675 & 0.150 & 0.150 \\
\hline$t^{\prime}$ & $(6.800)$ & 6.800 & 6.800 & 0.147 & 0.147 \\
\hline$t^{\prime \prime}$ & $(6.380)$ & 6.380 & 6.380 & 0.157 & 0.157 \\
\hline$t^{\prime \prime \prime}$ & $(7.170)$ & 7.170 & 7.170 & 0.139 & 0.139 \\
\hline$\lambda$ & $(0.330)$ & 0.383 & 1.789 & 3.030 & 1.058 \\
\hline$\gamma^{\prime} \quad$ & $(0.250)$ & 0.253 & 62.020 & 4.000 & 0.848 \\
\hline$\gamma^{\prime \prime \prime}$ & $(0.270)$ & 1.786 & 4.372 & 3.683 & 2.819 \\
\hline$\varepsilon$ & $(0.250)$ & 13.153 & 33.695 & 3.791 & 2.494 \\
\hline$\eta^{\prime}$ & $(0.250)$ & 0.252 & 25.412 & 4.000 & 1.080 \\
\hline & $(0.150)$ & 0.150 & 5.224 & 6.667 & 3.146 \\
\hline & $(0.150)$ & 0.150 & 0.570 & 6.667 & 3.119 \\
\hline$\omega$ & $(0.420)$ & 0.942 & 4.491 & 2.378 & 0.873 \\
\hline$\beta^{\prime \prime}$ & $(0.420)$ & 2.208 & 3.377 & 2.371 & 1.005 \\
\hline$\psi$ & $(0.350)$ & 0.720 & 49.956 & 2.854 & 0.744 \\
\hline$\gamma^{\prime \prime}$ & $(0.250)$ & 11.926 & 30.553 & 3.811 & 2.611 \\
\hline$\eta^{\prime \prime \prime}$ & $(0.250)$ & 0.250 & 0.533 & 4.000 & 2.434 \\
\hline o & $(0.010)$ & 8.743 & 23.909 & 11.768 & 2.923 \\
\hline
\end{tabular}

Compliance constants on the other hand possess the certain type of invariance properties which make it more feasible to associate them with the appropriate coordinates. We produced the compliance matrix for species $A_{1}$ by inverting the $F$ matrix block. The compliants received reasonable values both when excluding (except $r^{\prime \prime}$, III) and including (IV) the redundants, see Table 7 column III and IV. It is pleasing to observe that the compliants for $d^{\prime \prime}$ and $s$ coordinates are of the same magnitude in the two columns despite a factor of five between the $d^{\prime \prime}$ and $s$ related $F_{i i}$ values in column II. Corresponding compliants for the $\mathrm{PMo}_{12} \mathrm{O}_{40}^{3-}$ ion obtained values of the same order. The compliants for all the terminal oxygens are also very close to those obtained for the $\mathrm{PMo}_{12} \mathrm{O}_{40}^{3-}$ ion [15]. The obtainment of very similar values of the compliants in these two cases, despite different $F$ matrices, is an indication of a correct treatment in both calculations.

\section{Comparison with Observed Frequencies}

In the present analysis the force constants for the angles are adjusted tosuit the polarized Raman frequencies [9] as closely as possible. It is seen in Table 8 that only one of the polarized frequencies is missing $\left(489 \mathrm{~cm}^{-1}\right)$ for the species $A_{1}$. The other 6 frequencies are very close, and differ by $3 \mathrm{~cm}^{-1}$ at most. The 554 peak was found to belong to the $\lambda$ coordinate, and has served as a "calibration point" for the force constants of the angles. The calculated frequencies are distributed in the same ranges as the experimental, except for a range $450-500 \mathrm{~cm}^{-1}$ and for very low values. The very low frequencies are obtained for solids and may be due to solid state effects, and thus may not be genuine internal vibrations. It is interesting to see that in ranges where many peaks are observed, a great number of calculated frequencies are also obtained. A tentative description is given in the table and as expected, the terminal stretchings, $v_{\mathrm{MIO}-\mathrm{O}_{\mathrm{t}}}$, correspond with the highest frequencies.

\section{Acknowledgement}

We thank Dr. Michael Sharp for revision of the English text. The work forms part of a program financially supported by the Swedish Natural Science Research Council. 
Table 8. Calculated and observed frequencies, $v / \mathrm{cm}^{-1} /$ for the heptamolybdate anion.

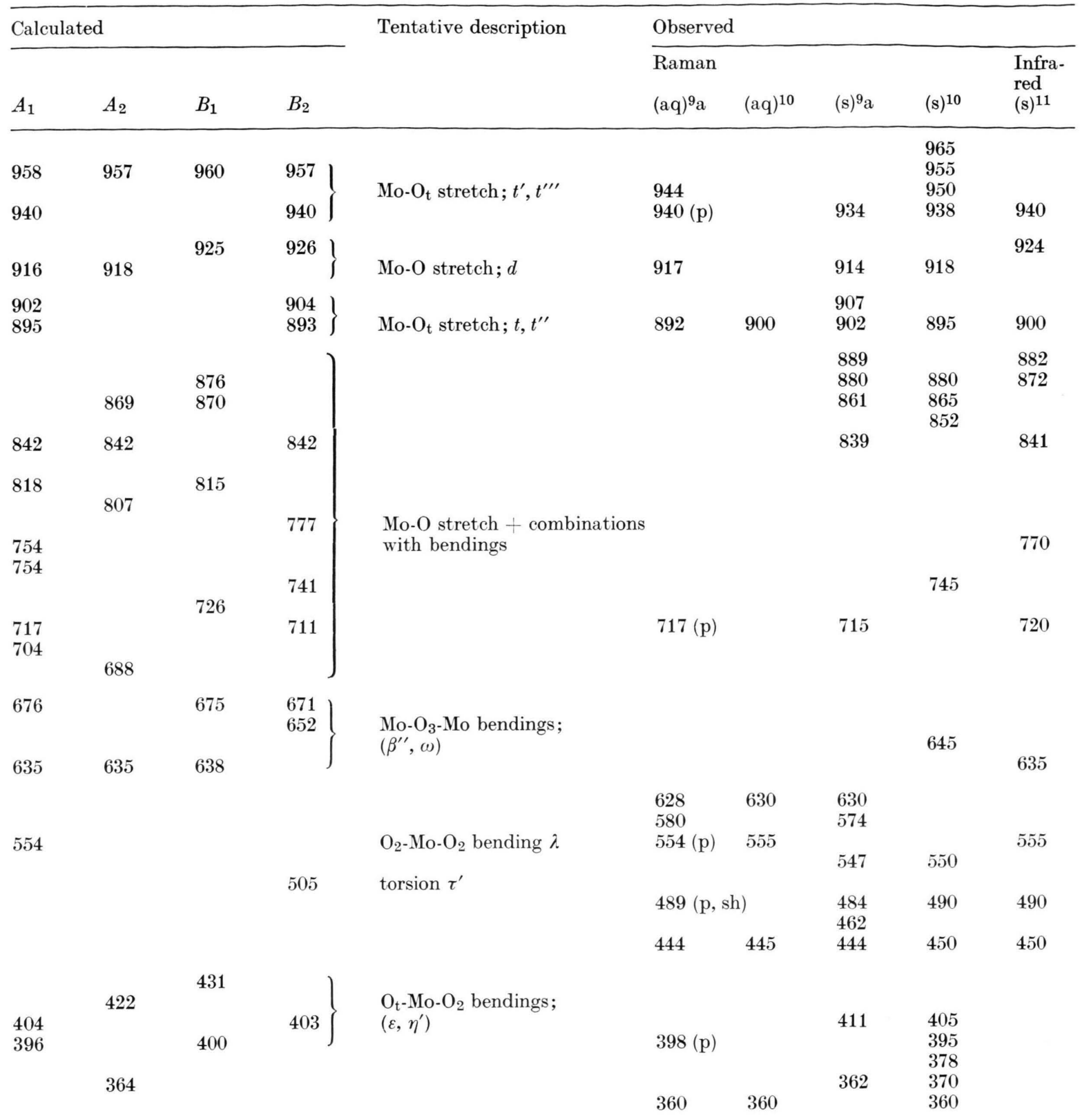


Table 8 (continued).

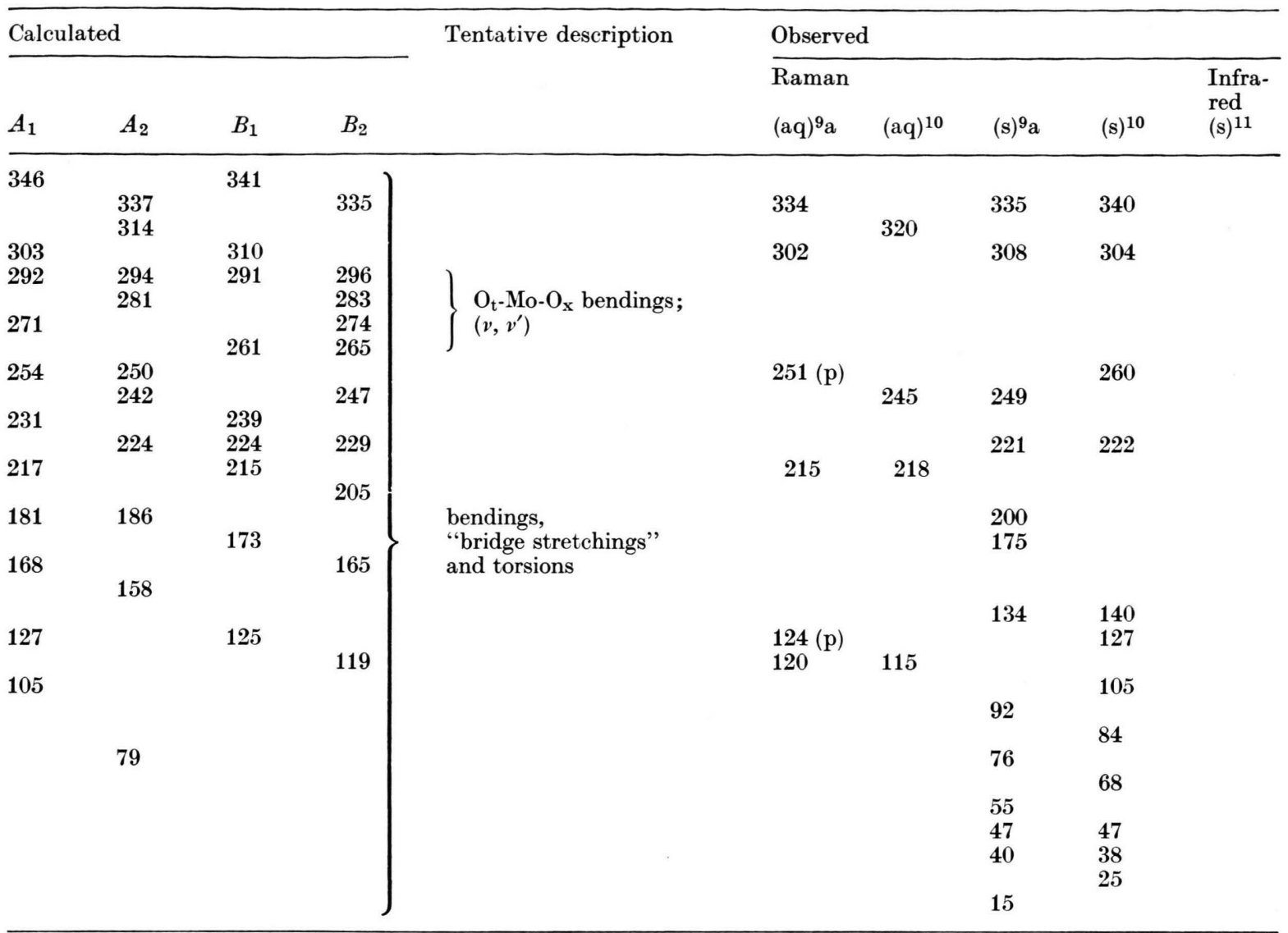

a frequencies for $\left(\mathrm{NH}_{4}\right)_{6} \mathrm{Mo}_{7} \mathrm{O}_{24} \cdot 4 \mathrm{H}_{2} \mathrm{O}$ and its solution. $\mathrm{p}=$ polarized; $\mathrm{sh}=$ shoulder.

[1] K. Sjöbom and B. Hedman, Acta Chem. Scand. 27, [11] L. Lyhamn, Chemica Scripta, 12, 153 (1977). 3673 (1973).

[2] I. Lindqvist, Arkiv Kemi 2, 325 (1950).

[3] Y. Sasaki and L. G. Sillén, Acta Chem. Scand. 18, 1014 (1964).

[4] G. Johansson, L. Petterson, and N. Ingri, Acta Chem. Scand. A 28, 1119 (1974).

[5] F. A. Miller, G. L. Carlson, F. F. Bentley, and W. H. Jones, Spectrochim. Acta 16, 135 (1960).

[6] J. Aveston, E. W. Anacker, and J. S. Johnson, Inorg. Chem. 3, 735 (1964).

[7] B. Schönfeld, Thesis, Göttingen 1973.

[8] K.-H. Tytko and B. Schönfeld, Z. Naturforsch. 30b, 471 (1975).

[12] a) S. J. Cyvin, Z. Anorg. Allg. Chem. 403, 193 (1974). (b) S. J. Cyvin and L. Lyhamn, J. Mol. Struct. 25, 151 (1975); erratum: ibid. 28, 452 (1975). c) R. Andreassen, S. J. Cyvin, and L. Lyhamn, J. Mol. Struct. 25, 155 (1975).

[13] S. J. Cyvin, B. N. Cyvin, R. Andreassen, and A. Müller, J. Mol. Struct. 25, 141 (1975).

[14] L. Lyhamn, S. J. Cyvin, B. N. Cyvin, and J. Brunvoll, Spectroscopy Letters, 9, 859 (1976).

[15] L. Lyhamn, S. J. Cyvin, B. N. Cyvin, and J. Brunvoll, Z. Naturforsch. 31 a, 1589 (1976).

[9] W.-D. Hunnius, Habilitationsschrift der Freien Universität Berlin (1977).

[10] L. Lyhamn and L. Petterson, Chemica Scripta, 12, $142(1977)$

[16] L. Lyhamn and S. J. Cyvin, Spectroscopy Letters 10, 907 (1977).

[17] E. B. Wilson, J. C. Decius, and P. C. Cross, Molecular Vibrations, McGraw-Hill, New York 1955.

[18] F. A. Cotton and R. M. Wing, Inorg. Chem. 4, 867 (1965). 